\title{
Information as Determinant of Utilization of Family Planning Services in Rural Akwa Ibom State of South-South Nigeria
}

\author{
Dr. Itimitang Wilson Etukudo \\ Department Of Political Science and Sociology, Western Delta University Oghara, Nigeria \\ Email:dritimitang@yahoo.com
}

\section{Doi:10.5901/mjss.2015.v6n4s1p445}

\section{Abstract}

Sources and nature of family planning information have been found to influence the use of family planning services. Unfortunately, the exact relationships between these variables and family planning utilization are not certain in Nigeria. This paper therefore searches for better understanding of the interrelationships, using rural Akwa Ibom State as the study area. Data analyses show that utilization of family planning information was greatest among respondents who received information from credible sources and those who were exposed to accurate and reliable information. The implications of the findings are discussed and some useful suggestions made.

Keywords: Information, Utilization, Family Planning, Rural, Determinant.

\section{Introduction}

Family planning and reproductive health programmes have contributed greatly to fertility decline in developing countries (Hong, 2006; Leete and Alam, 1999). Both sources and nature of family planning information are believed to have contributed to the use, non-use and discontinuation from the use of family planning services and also are capable of influencing the behaviour of the clients in many developing countries. Clients deserve, to receive accurate information about family planning and the information should come from credible sources (Murkherjee, 1974, Stewart and Llera, 1991).

In the developing countries, scholarly investigations into the relationships between nature and sources of family planning information and utilization of family planning services are hard to find and scholars have not been keen at taking up these challenges.

A common refrain in the literature is that clients' perception of practices and behaviour of family planning providers influences use of contraceptive methods (Koeing et al, 1997). Another is availability of a broader range of contraceptive methods which increases utilization of contraceptive methods and which inturn increases utlitzation of contraceptives through expanding method choice (Greenspan, 1991, Greenwell, 1996 and Thang and Huong, 2003). Other indicators associated with the quality of family planning services include availability of infrastructure and efficacy of the services (Bruce, 1990, Finger, 1993, Lesile and Gupta, 1989; and Hong et al, 2006,).

Both sources and nature of family planning information have been found to influence utilization of family planning services. But the exact relationships between these variables and family planning utilization in Nigeria are uncertain; it becomes imperative therefore to search for a better understanding of the interrelationships. Based on the above viewpoint, it is hypothesized that there is no significant differential in family planning levels of utilization between people who receive family planning information from credible sources and those who receive from non- credible sources. It is also hypothesized that there is no significant differential in family planning levels of utilization between people who are exposed to favourable information about family planning and those who are exposed to unfavourable rumours.

Based on the above, the following are the objectives of this study;

1. To examine the relationship between sources of family planning and its utilization.

2. To examine the relationship between nature of family planning information and family planning utilization.

With regards to the significance of the study, it adds to the literature on the relationships between family planning services utilization, sources of information about family planning and the nature of such information. The research is indeed needed regarding the best approach for reaching people in traditional settings (such as that of Akwa lbom State) with the view to legitimizing family planning and other reproductive health issues as well as resolving differences in their family planning desires. This is very important because within the study area, there may be evidence of latent desire for 
fertility control among those who never practiced family planning and would want to control their family size. By helping people who need family planning to have access to right and accurate information, Nigeria's family planning programme in general and that of Akwa Ibom State in particular may have a greater impact of fostering ideational change and helping couples and others meet their reproductive goals.

\section{Methodology}

\subsection{The study area}

This study was carried out in Akwa Ibom State of South-South Nigeria. Akwa Ibom State is found between latitude 403' N and $5^{0} 3^{\prime} \mathrm{N}$ and longitude $70^{\circ} \mathrm{E}$ and $8015^{\prime} \mathrm{E}$. it has three major ethnic groups (namely; Ibibio, Annang and Oron) with a total population of $3,920,208$ spread across a landmass of $8,412 \mathrm{~km}^{2}$. The economically and actively employed population constitutes $48.5 \%$ (Ekong, 2003). A majority of the people in the state (most especially in the rural areas) are predominantly illiterate.

The people of Akwa Ibom State speak diverse languages reflecting the socio-cultural and ethnic background of the state. The common language understood by all the ethnic groups is the lbibio language.

There are 31 Local Government Areas in the state, each administered by a group of representatives at their respective council headquarters. Uyo is the headquarters of the State and it forms the cynosure, which attracts the rural people from different parts of the state for greener pastures (Akpabio, 2006).

Just as in other States in Nigeria, a few modern healthcare facilities exist in the rural areas of Akwa lbom State. These health facilities are ill-equipped in terms of drugs, equipments and personnel. They (rural areas) also lack basic social amenities such as good roads and modern communication facilities.

Fertility levels are high in the State, especially in the rural areas. Total fertility rate and the desired family size for the area are 8.1 and 6.7 respectively. These figures point to the need for increased family planning programmes in the area.

\subsection{Literature Review}

Family planning studies indicate that sources and nature of information about family planning in all ramifications are very important as far as its utilization is concerned in any communities be it urban or rural (Pakistan Academy of Family Planning, 1969). For these to be the gateway for family planning utilization, the messages about it need to be adequate and understandable. On the sources of family planning information, Duze and Mohammed, (2006) opined that friends, relatives and neighbors as sources of family planning may be harmful. These sources are characterized by unfavourable rumours about family planning. These sources emphasis side effects of family planning as means of discouraging people from adopting and using contraceptive methods. MuKerjee (1974) identified health workers, radio, television, newspapers and non-governmental organizations (dealing with family planning issues) as those sources that carry positive views about family planning. They are credible sources. Information from them about family planning are always accurate, correct and unbiased. People who are exposed to messages from these sources are more likely to accept and practice family planning than those exposed to information from friends, relatives and neighbors (Mukherjee, 1974). Prospective family planning acceptors need information about family planning before a decision on whether to practice or not are taken (Moreno and Goldman, 1991; Bicknell and Walsh, 1976). Contraceptive use is related to exposure to information about family planning (Arnold, 1972). Lack of information, incorrect or incomplete information and misinformation are constraints to the use of family planning (Senderowitz, 1994; Schuler, 1985 and Basu, 1984). Unfavorable rumours affect the use of family planning (Stewart and Sommerfelt, 1991). Corsa and Oakley (1979) identified knowledge about reproduction and why birth control is a necessary part of planned reproduction, knowledge about the way to use family planning methods, where to obtain family planning services, and knowledge about both costs and benefits of children as important family planning information components. Park etal (1977) and Sakaran (1994) averred that for people to use family planning, they need information and knowledge about the available family planning services. Women's lack 0 knowledge about these important family planning information components may deter them from using contraceptives (Presser, 1974). Women's perception of the risks of contraceptives and awareness of unfavourable rumours about contraception may widely lead to its non-utilization and discontinuation. Celbard and DeBarragan, 1991; Llera, 1991; Bobadilla, etal; 1990; Hill and Pebley, 1989 and Hobcraft, 1987). Baldwin and Ford (1976) found Sheer lack of knowledge and information about family planning most especially the methods available to be the chief obstacle to effective use of family planning in Columbia. 
In this analysis of demographic data from some developing countries, Ross (1995) observed that half of the women not using contraception in low prevalence countries lacked knowledge about contraceptives. In their study of North Indian State, Laurghrin et al (1994) noted that lack of accurate information and knowledge about specific contraceptive methods and unfavourable rumours were responsible for low rate of utilization of family planning among the studied population.

\subsection{Data Collection}

This study was conducted among women aged between 15 and 49 years in the rural area of Akwa Ibom State. The study was restricted to six Local Government Areas. The selection of Local Government Areas was made to reflect the socioethnic backgrounds of the state. Two villages were selected from each of the six local government areas. The twelve village provided the 952 respondents used in the study. The sample size was considered adequate because the homogeneous nature of the population. In order to achieve accurate and representative sample size for the entire population under study, a combination of simple random sampling and multi-stage sampling technique was used. The use of simple random sampling technique was to avoid bias in the selection of elements. Since list of households in the study areas were not readily available, multi-stage sampling technique was also used. The first stage was the selection of local government areas from the three senatorial districts. The second was the selection of the villages from the local government areas and finally the selection of the households from which the respondents were interviewed. The selection of the households was done through the use of systematic sampling technique. This method was preferred because it was efficient and required less time, thus permitting data to be collected in the absence of lists of households in the streets selected from where respondents were selected. Twelve trained field assistants who were all females conducted interviews in the local language. They were undergraduate students of the University of Uyo. The field assistants were natives of the twelve local government areas from which the respondents were drawn. This was particularly useful in the overcoming ethnic and cultural barriers in each of the study areas, because being their confidentiality was assured. Structured interview was used to collect past and current data. The interview schedule contained questions on respondents' socio-demographic characteristics. Questions concerning family planning knowledge and use levels as well as those about the nature and sources of family planning information were also asked. Respondent's responses to questions were interpreted through the use of or simple percentage: Since the data were largely categorical, the $\times 2$ was used to test the research hypotheses. To test the strength of relationship, a measure of association Phi-Coefficient ( $\phi$ ) was used. In order to accept or reflect the null hypotheses, the significant level of 0.05 was used.

\section{Findings}

Table 1: Percentage distribution of respondents by socio-demographic characteristics

\begin{tabular}{|c|c|c|}
\hline Socio-demographic Characteristics & No of Respondents & Percentage \\
\hline Age: & & 8.8 \\
\hline $15-19$ & 326 & 24.8 \\
\hline $20-24$ & 314 & 33.0 \\
\hline $25-29$ & 228 & 33.4 \\
\hline $30+$ & & \\
\hline Education & 210 & 22.1 \\
\hline Higher Education & 206 & 21.6 \\
\hline Secondary School & 310 & 32.6 \\
\hline Primary School & 226 & 23.7 \\
\hline No formal education & & 3.8 \\
\hline Occupation: & 36 & 25.2 \\
\hline Teaching & 240 & 9.7 \\
\hline Farming & 92 & 5.7 \\
\hline Clerical (White collar) & 54 & 25.0 \\
\hline Job & 290 & 20.3 \\
\hline Business & 240 & 62.0 \\
\hline Home keeping & & \\
\hline Religion: & 590 & \\
\hline Protestant & & \\
\hline
\end{tabular}




\begin{tabular}{|c|c|c|}
\hline Catholic & 354 & 37.2 \\
\hline African Traditional & 8 & 0.8 \\
\hline Marital Status: & & \\
\hline Married & 647 & 68.0 \\
\hline Unmarried & 305 & 32.0 \\
\hline Number of Living Children & & 11.3 \\
\hline 1 & 108 & 10.9 \\
\hline $2-3$ & 104 & 21.9 \\
\hline $4-5$ & 208 & 45.6 \\
\hline $6-7$ & 434 & 10.3 \\
\hline $8+$ & 98 & \\
\hline
\end{tabular}

Data for the socio-demographic characteristics of the respondents show that the respondents were aged 15 to 49 years. A majority of them were aged between 20 and 29 years (see Table 1). In terms of education, almost one-fifth of the respondents had gone beyond secondary school level while 23.7 percent had no formal education. When occupation is considered, table 1 shows that most of the respondents were farmers, home keepers and petty traders. They represent 25.3 percent, 25.0 percent and 30.3 percent respectively. Table 1 also shows that a majority (99.2 percent) of the respondents were Christians while negligible percentage (0.8\%) were worshippers of African Traditional Religion. In terms of marital status, the table shows that 68 percent of the respondents were married while 32 percent were unmarried. With regards to the number of living children, 45.6 percent of the respondents had between six and seven children. About 22.2 percent had between one and three children while 10.3 percent had eight children and above.

\section{Contraceptive Knowledge and Use}

Table 2: Percentage Distribution of Respondents by Knowledge of any Family Planning Methods

\begin{tabular}{|l|c|c|}
\hline Any Methods Known & No. of Respondents & Percentage \\
\hline Traditional Methods & 358 & 37.6 \\
\hline Modern Methods & 475 & 49.9 \\
\hline No. Knowledge & 119 & 12.5 \\
\hline Total & 952 & 100.0 \\
\hline
\end{tabular}

Table 2 indicates that majority (87.5\%) of the respondents reported knowing contraceptive methods. Knowledge of modern methods (49.9\%) was higher than that of traditional methods $37.6 \%$. Almost $13 \%$ of the respondents had no knowledge of any method.

Table 3: Percentage Distribution of Respondents by Family Planning Methods

Ever used.

\begin{tabular}{|l|c|c|}
\hline Ever used Method & No. of Respondents & Percentage \\
\hline Traditional Methods & 161 & 16.9 \\
\hline Modern Methods & 307 & 32.3 \\
\hline Never used any method & 484 & 50.8 \\
\hline Total & 952 & 100.0 \\
\hline
\end{tabular}

Table 3 shows that $49.2 \%$ of the respondents have ever used family planning method while $50.8 \%$ have not used it. Those who have used traditional methods were $16.9 \%$ while those who have used modern methods were $32.3 \%$.

Table 4: Percentage Distribution of Respondents by Current use of Family Planning Methods

\begin{tabular}{|l|c|c|}
\hline Current use & No. of Respondents & Percentage \\
\hline Traditional Methods & 101 & 10.6 \\
\hline Modern Methods & 198 & 20.8 \\
\hline Not using any Method & 653 & 68.6 \\
\hline Total & 952 & 100.0 \\
\hline
\end{tabular}


Table 4 indicates that $31.4 \%$ of the respondents were currently using family planning methods. Out of this, users of traditional methods were $10.6 \%$ while those using modern method were $20.8 \%$. Almost $69 \%$ were not using any method.

\subsection{Relationship between sources of family planning and its Utilization}

Concerning the relationship between sources of family planning information and Utilization of family planning Services, the results of the study show that utilization of family planning services are higher among respondents who received information about family planning from credible sources such as hospitals, health centres, health workers, patent medicine stores and the mass media.

Tables 5 and 6 show that out of the 468 respondents who had used family planning services, 454 of then received family planning information from credible sources, and out of this number, 398 (87.7 percent) had used family planning, while 56 (12.3 percent) had never used family planning. The tables further indicate that of the 498 respondents who received family planning information from non-credible sources such as: friends, churches, neighbours, husbands and wives only 70(14.1 percent) had used family planning while 428 (85.9 percent) had never used family planning.

On further statistical analysis of the relationship between sources of family planning information and utilization of family planning services, Table 6 which is the summary of Table 5 shows it to be significant $\left(X^{2}=514.8, d / f=1, P\right.$ $>0.05$, see table 6). To further test the strength of the result, Phi-Coefficient was used and the obtained value was 0.73 (see table 7) which showed that there is a significant strong differential in family planning levels of utilization between those who received family planning information from credible sources and those who received from non- credible sources.

Based on the above results, we can say that the practice of family planning in rural areas (especially the study area) is affected by the sources from which people get their family planning information.

Table 5: Distribution of respondents according to sources of family planning information and utilization

\begin{tabular}{|c|c|c|c|}
\hline & \multicolumn{2}{|c|}{ Utilization } & Total \\
\hline Sources of family Planning information & Ever used & Never used & 160 \\
\hline Hospitals and Health Centres $^{*}$ & 142 & 18 & 88 \\
\hline Health workers* & 72 & 16 & 78 \\
\hline Patent Medicine Stores* $^{*}$ & 64 & 14 & 128 \\
\hline Mass Media* & 120 & 8 & 90 \\
\hline Friends & 6 & 84 & 124 \\
\hline Neighbours & 14 & 110 & 94 \\
\hline Churches & 4 & 90 & 120 \\
\hline Members of the Family & 18 & 102 & 70 \\
\hline Husbands/Wives & 28 & 42 & 956 \\
\hline
\end{tabular}

Note: *Credible sources of family planning information. Those sources not asterisked are non-credible sources.

Table 6: Summary of Table 5.

\begin{tabular}{|c|c|c|c|c|}
\hline Sources of family Planning information & \multicolumn{2}{|c|}{ Utilization } & Total & $X^{2}$ \\
\hline & Ever used & Never used & & \\
\hline Credible & $398(223.3)^{\star}$ & $56(230.6)$ & 454 & 504.8 \\
\hline Non-credible & $70(244.8)$ & $428(253.2)$ & 498 & \\
\hline Total & 468 & 484 & 952 & \\
\hline
\end{tabular}

$\mathrm{X}^{2}=504.8, \mathrm{df}=1$; significant at 0.05 level.

Table 7: Phi-coefficient Test of the strength of the relationship between sources of family planning information and utilization of family planning services.

\begin{tabular}{|l|c|c|c|}
\hline Variables & $\mathrm{N}$ & $\mathrm{X}^{2}$ & $\varnothing$ \\
\hline Relationship between sources of family planning information and utilization of family planning services. & 952 & 514.8 & 0.73 \\
\hline
\end{tabular}




\subsection{Relationship Between Nature Of Family Planning Information And Family Planning Utilization}

With regards to the relationship between the nature of family planning information to which people were exposed to and utilization of family planning services, the results of this study show that there is a significant difference in the use of family planning services between those who were exposed to official sources of information about family planning and those who were exposed to non-official sources of information.

Tables 8 and 9 indicate that out of the 446 (46.9 percent) respondent who were exposed to favourable planning information,390 (87.4 percent) had used family planning while 56 (12.6 percent) had never used family planning. The Tables also show that of the 506 (53.21 percent) respondents who received or were exposed to unfavourable rumours, 428 (84.2 percent) had never used family planning, and 78 (15.4 percent) had used family planning. On further statistical analysis of the relationship between the nature of family planning information people were exposed to and utilization of family planning services, Table 9 which is the summary of Table 8 shows it to be significant $\left(X^{2}=492, d / f=1, P<0.05\right.$, see Table 9).

To further test the strength of the result. Phi-coefficient was used and the obtained value was 0.72(see Table 10) which showed that there is significant strong differential in family planning levels of utilization between people who are exposed to favorable information about family planning and those who are exposed to unfavorable rumors. From the above result, we can conclude that, utilization of family planning in rural areas (especially the study area) is affected by the nature of information people are exposed to.

Table 8: Distribution of respondents according to the nature of family planning information they are exposed to by their family planning status.

\begin{tabular}{|c|c|c|c|}
\hline \multirow[t]{3}{*}{ Nature of family Planning information they are exposed to } & \multirow{2}{*}{\multicolumn{2}{|c|}{ Utilization }} & \multirow[b]{2}{*}{ Total } \\
\hline & & & \\
\hline & Ever used & Never used & \\
\hline A good method that allows people to have the number of children that they would be able to cater for. * & 130 & 12 & 142 \\
\hline A practice that promotes good health of mothers and children* & 98 & 16 & 114 \\
\hline A practice that allows people to avoid contacting sexually transmitted diseases/AIDS* & 54 & 10 & 64 \\
\hline A method that allows parents to progress in life* & 108 & 8 & 126 \\
\hline It is against the will of God & 8 & 30 & 38 \\
\hline It is something that can make a society Immoral & 10 & 38 & 48 \\
\hline It is against our tradition & 6 & 34 & 40 \\
\hline It can bring havoc among the people from the gods, goddess and deities & 4 & 24 & 28 \\
\hline It makes women to become barren for life & 6 & 46 & 52 \\
\hline It is difficult to get a good method & 2 & 28 & 30 \\
\hline It is costly & 12 & 86 & 98 \\
\hline It exposes women to ridicule & 6 & 34 & 40 \\
\hline If you die with it you will not become Pregnant in the nest generation. & 12 & 48 & 60 \\
\hline family planning methods (especially modern) are dangerous to the health of mothers and children & 12 & 60 & 72 \\
\hline Total & & 484 & 952 \\
\hline
\end{tabular}

Note: *Favourable information about family planning. Those information not asterisked are favourable rumors about family planning.

Table 9: Summary of Table 8

\begin{tabular}{|l|c|c|c|c|}
\hline Nature of family Planning Information they are exposed to & \multicolumn{2}{|c|}{ Utilization } & Total & $X^{2}$ \\
\hline & Ever used & Never used & & \\
\hline Favourable Information & $390(219.2)^{\star}$ & $56(226.8)$ & 446 & 492.2 \\
\hline Unfavourable information & $78(248.8)$ & $428(257.2)$ & 506 & \\
\hline Total & 468 & 484 & 952 & \\
\hline
\end{tabular}

$\mathrm{X}^{2}=492.2 ; \mathrm{df}=1$; significant at 0.05 level. 
Table 10: Phi-coefficient test of the strength of the relationship between nature of family planning information people are exposed to and utilization of family planning services.

\begin{tabular}{|l|c|c|c|}
\hline Variables & $\mathrm{N}$ & $\mathrm{X}^{2}$ & $\varnothing$ \\
\hline $\begin{array}{l}\text { Relationship between sources of family planning information people are exposed to and utilization of family } \\
\text { planning services }\end{array}$ & 952 & 492.1 & 0.72 \\
\hline
\end{tabular}

Note: Significant at 0.05 .

\section{Discussion and Conclusion}

The results of this study show a strong relationship between the sources of family planning information, and the nature of family planning information people are exposed to, and family planning utilization. These are similar to the findings of some scholars Laurghrin et al, (1994). note that lack of accurate information and knowledge about specific contraceptive methods and unfavourable rumours among villagers were responsible for the low rate of utilization of family planning among the studied populations. This is also shared by Celbard and De-Barrangan (1991) who noted that women's perceptions of the risks of contraceptives and awareness of unfavourable rumours about contraceptives may likely lead to their non- utilization and/or discontinuation.

Rumours and misinformation are widespread in many developing countries and they seen to be major barriers to contraceptive use (Bodadilla, et al, 1990; Ayad and Wikinson, 1999; Llerra, 1999; Hill and Pebbley, 1989). For example, in eight developing countries between 6 and 54 percent of women (aged 18 - 45) had never used oral contraceptives because of safety worries (Bobadilla, et a1, 1990).

In their study, in the Dominican republic, Steward and Sommerfelt (1991) found that unfavourable rumours led to the discontinuation of a variety of effective methods. The findings show that, first-time users were more affected than those who had used modern methods before. Women who had fears about modern contraception and those who experienced side effects also were more likely to discontinue after hearing unfavourable rumours. These results highlight the importance of giving new users accurate and complete information (Steward and Sommerfelt, 1991). Browner (1971) using data from a survey he conducted in Columbia observes that women mentioned the negative experiences of friends and relatives about contraceptives as reasons for not using family planning. Focus Group Discussions on family planning cited rumours of side effects as the reason they do not practice contraceptive. These were wrong pieces of information acquired from friends, family members and church members and other inaccurate sources as neighbours, husbands and wives who abhor family planning. For example, 42 percent of the women were told that oral contraceptives stopped a woman from having another baby, and 35 percent thought that intra uterine devices (IUDs) caused internal bleeding. Half of the participants said they knew nothing about family planning and wanted information about it. Family planning users and non-users who said they knew something about family planning wanted to know more about its side effects, safety and effectiveness of methods (Harbison and Robinson, 1991).

In his study, in two communities in India, Mukkerjee (1974) reported that 44.7 percent of the surveyed population gave reason that reflect either inadequate or improper knowledge about family planning methods as reasons for not practicing family planning. This was attributed to sources of information and messages about family planning. According to him, a majority of respondents cited friends, relatives and neighbours as their sources of information on family planning. He pointed out that these sources may be harmful in the absence of more trustworthy and credible sources of information such as the media. According to him when users or would-be users come in contact with uninformed sources they may also develop negative views about family planning which can make them to abhor it. Thus, they may drop the idea of using family planning or be discouraged from continued use if they were practicing it. Health workers (who are not biased about family planning), radio, non-governmental organizations (concerned with family planning matters), the television, etc, carry positive views about family planning. Information dished out to members of the public by these sources are always based on informed knowledge about family planning, thus, they are always accurate, correct and unbiased. These sources constitute credible sources of family planning information. Because of this fact, people exposed to messages and information from them are more likely to use family planning than those who receive information about family planning from non-credible sources (Mukkherjee, et al, 1974).

In the opinion of Hobcraft (987), Bodadilla, et al (1990); Llera (1990; Steward and Sommerfelt, (1991) and Ayad and Wilkinson (1991), approval of contraception by relations and friends is also significantly related to contraceptive use. Developing interventions to improve the unfortunate situation of people whos may want to use contraception, but have never been exposed to adequate and reliable information about the subject is a challenge to policy makers and service providers in the study area in particular and Nigeria in general. 
Although no research has directly addressed the issue, counseling may be one of the best means to combat rumours and misinformation which affect the utilization of family planning among the rural people of Akwa Ibom State in particular and Nigeria in general as indicated by the research findings. Just like other areas in Third World countries, rumours and misinformation about family planning are widespread in rural areas of Akwa Ibom State. For example, the research findings showed that negative rumours are common among the rural people of Akwa lbom State; such rumours include ideas that family planning makes a woman to be barren in life; it is dangerous to health of mothers and children, it is something that can make a woman who used it not to become pregnant in the nest generation, it is something that can make a couple to be promiscuous, it is something that can bring punishment from gods, etc. While many believed these false notions, others were aware of the good aspects of family planning such as that family planning helps couples to control the number of children they have; promotes good health of mothers and children, helps couples to avoid contacting sexually transmitted diseases and helps parents to progress in life.

To combat these negative rumours and misinformation about family planning, family planning counseling should be carried out among the people. This should be seen as a special type of person-to-person communication between family planning providers, motivators and communicators and eligible users who have been identified by the former persons involved in family planning campaigns. Good counseling at clinics through community- based distribution system would bring about informed choice of family planning among the people. Community level information channels can also contribute to informed choice about contraception; through public statements by influential health workers, opinion leaders and mass media campaigns in our rural communities. Good counseling which we advocate should ensure the establishment of trusting and caring relationship with clients and ensure that relevant and accurate information is given to and received from clients.

In order to achieve these, those involved in providing family planning services should always treat clients in a friendly and dignified way when interacting and providing services to them; ask them about their family planning needs; tell the clients the available methods, seek their opinion and help them to decide which methods they want; explain how to use the method chosen; assure them that any personal information will remain confidential and plan return visit with clients.

These are necessary because they help clients to make voluntary, informed and well-considered decisions about their reproductive lives and when these are observed by providers of family planning services, clients' needs will be addressed and better quality service will be provided. All these will lead to improved or higher family planning methods use and clients satisfaction with the services which will eventually lead to high use and continuation rates in the study area and others.

Finally, differences in sex, social class, economic status, education and cultural background between clients and providers can interfere with effective counseling. In rural areas, family planning providers should have the same background characteristics with the eligible women or potential users of family planning. This is important because women would be more likely to believe information about family planning regardless of actual content, if it is from a respected health worker who has the same background characteristics with the women. In Nigeria, especially in the rural areas, traditional birth attendants (TBAs) would serve a useful purpose in helping the people accept and practice family planning. In Nigeria today, traditional birth attendants are in the forefront of planning and execution of programmes like Expanded Programme on Immunization (EPI), Maternal and Child Health and Oral Rehydration Therapy (ORT) and other programmes. Traditional birth attendants had long introduced family planning in our rural areas. Their family planning services/methods are numerous and they include roots, herbal concoction, etc.

Since traditional birth attendants are caring, polite, older, female and personally known by rural people and are highly regarded as trustworthy they are more likely to be listened to, by the women, than modern health workers. Because of these qualities and because of paucity of modern health workers and facilities in our rural areas, there is an urgent need to incorporate greater number of TBAs as family planning providers. One important justification for incorporating TBAs in family planning programmes is to minimize their opposition to modern family planning and discourage them from initiating and spreading negative rumours.

\section{References}

Arnold, F. (1972) A Model relating Education to fertility in Taiwan. Unpublished Ph.D Dissertation, University of Michigan.

Ayad, M. and Wikinson, M. (1992). Sources of Contraceptive Methods. Columbia, Maryland Institute for Resources Development. Baldwin, W. and Ford, T.R. (1976) Modernism and Contraceptive use in Columbia. Studies in Family Planning 7(3):75-79.

Basu, A.K. (1984) Ignorance of Family Planning methods in India: An important constraint on use. Studies in Family Planning 15(3):136142

Bicknell, F.O. and Walsh, D.A. (1976) Motivation and Family Planning incentives and disincentives in the delivery system. Social Science 
and Medicine, 10: 579-583

Bobadilla, J. L., L. Schlacapper and Algon, J. (1990). Family Formation Pattern and Child Mortality in Mexico. New York: Population Council

Demographic and Health Surveys Further Analysis Series, 0. 5:63.

Browner, C. (1979). Abortion Decision-making: Some Findings from Columbia. Studies in Family Planning 10: 96-110.

Bruce, E. (1990). Fundamental elements of the quality of care: A simple framework. Studies in Family Planning 21(2): 61 -91.

Celbard, A. H. and Debarragen, L. (1991). Policy Implications of the 1989 Bolivia Demographic and Health Surveys. In Demographic and Health Surveys World Conference Proceedings Vol. 3: 1957-1978.

Washington, D. C. Columbia, Maryland, U. S. A.

Corsa, L. and Oakley, D. (1979) Population Planning. Ann Arbor: The University of Michigan Press.

Duze, M.C. and Mohammed, I.Z. (2006) Male knowledge, Attitudes and Family Planning Practices in Northern Nigeria. Africa Journal of Reproductive Health 10(3):53-65.

Ekong, E. E. (2003). An Introduction to Rural Sociology. Uyo, Dove Educational Publishers.

Enoh, E. O. E. (1997). An Introduction to Empirical Research in Social Science and the Humanities: Uyo: MFE (Nigeria) Ltd.

Finger, W. R. (1993). Choice, Access, Information and Among Clients' Right Network 114(1): 24-26.

Greespan (1991). Adding Choice to the Contraceptive Mix: Lesson from Indonesia. Asia-Pacific Population Policy 19:1-4.

Greenwell, K. F. (1996). Contraceptive Method Mix Menu: Providing Healthy Choice for Women. World Health Statistics Quarterly 49 (2): 88-93.

Harbison, S. F. and Robinson, W. C. (1991). Components of the Recent Fertility decline in Kenya. International Family Planning Perspective 14(2): 34-44.

Hill, K. and Pebley, A. R. (1989). Child Mortality in the Developing World. Population and Development Review 15(4): 657-687.

Hobcraft, J. (1987). Do Family Planning Save Children's Lives? Technical Background. Paper Prepared for the International Conference on

Better Health for Women and Children through Family Planning, Nairobi, Kenya.

Hon, R; Montana, L. and Mishra, V. (2006). Family Planning Services Quality as Determinants and Use of IUD in Egypt. Health and Services Research 6 (79).

Kar, B. S. , Talbot, J. M. B. and Whittaker, M. (1997). The Influence of Quality of Care upon Contraceptive; A Cross Cultural Study. Studies in Family Planning 11(2): 51-64.

Koeing, M. A; Hossain, ., M. B and Whittaker, M. (1997). The Influence of Quality of Care upon Contraceptive Use in Rural Bangladesh.

Studies in Family Planning 28 (4): 278-289.

Laughrin, A; Seligman, B; Burton, N. and Hanlon, B. (1994). Reproductive health services in Central Asia. Findings from a Survey Provider.

Leete, R. and Alan, I. (1991). Asia's Demographic Miracle: 50 Years of Unprecedented Change. Asia pacific Population Journal 14 (4): 9-20.

Leslie, J. and Gupta, R. G. (1989). Utilization of Formal Services for Maternal Nutrition and Healthcare in the Third World. Washington D. C. International Centre for Research on Women.

Llera, S. (1991). Mexico: A Decade of Family Planning and Contraceptive Practice. In Demographic Health Survey World Conference. 1:343-366. Washington D. C., Columbia, Maryland, U. S. A

Misra, B. 0., Simmons, R; Ashraf, F. and Simmons, G. (1976). The Dilemma of Family Planning in a North India and Tamil Nadu, India. Studies in Family Planning 5 (7): 224-231.

Moreno, L. and Goldman, N. (1991) Contraceptive failure rates in Developing Countries: Evidence from the Demographic and Health Surveys. International Family Planning Perspective 17(2) 44-49

Murkherjee, B.N. (1974) A Comparison of The Results of Family Planning KAP surveys in Haryana and Tamil Nadu India. Studies in Family Planning 5(7):224-231

Pakistan Academy of Family Planning (1969) Survey of Attitude of Rural Population towards Family Planning In Inventory of Family Planning Research in Pakistan, Karachi: 163-164.

Park, C.B; Cho, L. and Palmore, J.A (1977) The Euiryong Experiment: A Korean Innovation in Household Contraceptive Distribution. Studies in Family Planning 8(3):67-76.

Presser, H.B. (1974) Early Motherhood: Ignorance or Bliss? Family Planning Perspective 6:8-14

Ross, J.A. (1995) The Question of Access. Studies in Family Planning 26 (4):241-242.

Sakaran, G. (1994) Ethical Issues in Family Planning: Rights of the client. In The 1994 National Council for International Health Annual Conference Abstract. Washington D.C; USA:A-38.

Schuler, S.R. (1985) Barriers to Effective Family planning-Nepal. Studies in Family Planning, 16(5):260-270.

Senderowitz, J. (1994) Reassessing the passage to adulthood: Issues and strategies for Young women's health. World Bank, Washington D.C.

Stewart, K. and Sommerfelt, A. A. (1991). Utilization Maternity Care Services: A

Comparative Study using Demographic and Health Services Data. Demographic and Health Survey World Conference Proceedings. Vol. 3. 1645 - 1668. Washington D. C., Columbia, Maryland, U. S. A.

Thang, N. M. and Huong, V. T. (2003). Changes in Contraceptives Use in Vietnam. Journal of Biological Sciences 35 (4): 527-543. 